\title{
The Cross-Talk between Age, Hypertension and Inflammation in COVID-19 Patients: Therapeutic Targets
}

\author{
${\text { Gerardo } \text { Casucci }^{1} \cdot \text { Domenico Acanfora }^{1} \cdot \text { Raffaele Antonelli Incalzi }}^{2}$
}

Accepted: 30 September 2020 / Published online: 21 October 2020

(c) Springer Nature Switzerland AG 2020

\begin{abstract}
This paper presents a brief overview of the complex interaction between age, hypertension, the renin-angiotensin-aldosterone system (RAAS), inflammation, and severe acute respiratory syndrome coronavirus 2 (SARS-CoV2) infection. Coronavirus disease 2019 (COVID-19) is more frequent and more severe in comorbid elderly patients, especially those with hypertension, diabetes, obesity, or cardiovascular diseases. There are concerns regarding the use of RAAS inhibitors in patients with COVID-19. Some physicians have considered the need for interrupting RAAS inhibition in order to reduce the possibility of SARS-CoV2 entering lung cells after binding to angiotensin-converting enzyme 2 (ACE2) receptors. We offer a different point of view in relation to the need for continuing to use RAAS inhibitors in patients with COVID-19. We focused our article on elderly patients because of the distinctive imbalance between the immune response, which is depressed, and the exacerbated inflammatory response, 'inflammaging', which makes the geriatric patient an appropriate candidate for therapeutic strategies aimed at modulating the inflammatory response. Indeed, COVID-19 is an inflammatory storm that starts and worsens during the course of the disease. During the COVID-19 pandemic, various therapeutic approaches have been tested, including antiviral drugs, interferon, anti-interleukins, hydroxychloroquine, anti-inflammatories, immunoglobulins from recovered patients, and heparins. Some of these therapeutic approaches did not prove to be beneficial, or even induced serious complications. Based on current evidence, in the early stages of the disease modulation of the inflammatory response through the inhibition of neprilysin and modulation of the RAAS could affect the course and outcome of COVID-19.
\end{abstract}

\section{Introduction}

The severe acute respiratory syndrome coronavirus 2 (SARS-CoV2) has spread quickly around the world, causing clusters of prevalent respiratory Coronavirus Disease 2019 (COVID-19), including acute respiratory distress syndrome (ARDS), and becoming a serious public health concern [1]. From the beginning of the COVID-19 pandemic to date, there has been a continuous updating of the pathogenetic mechanisms of the disease. From clinical, epidemiological, and radiological criteria, attention has been paid to the demodulation of the renin-angiotensin-aldosterone system (RAAS) and inflammation. At

Domenico Acanfora

domenico.acanfora29@gmail.com

1 Unit of Internal Medicine, San Francesco Hospital, Viale Europa 21, 82037 Telese Terme, BN, Italy

2 Unit of Geriatrics, Policlinico Universitario Campus Bio-Medico di Roma, Via Álvaro del Portillo 21, 00128 Rome, Italy

\section{Key Points}

Elderly patients, the most vulnerable to COVID-19, frequently have chronic diseases for which a renin-angiotensin-aldosterone system (RAAS) inhibitor is indicated

Inhibition of the RAAS could modulate the inflammatory response to COVID-19, thus decreasing the intensity of the cytokine storm

RAAS and neprilysin inhibitors might benefit COVID19 patients in the early stages of the disease through inflammatory response modulation. Inflammaging, i.e. an imbalance between immune and inflammatory response, makes such a mechanism of special interest for geriatric patients

present, there are no therapeutic recommendations applied worldwide. The counteracting of RAAS demodulation and inflammatory storm appear to be optimal approaches. 
The purpose of this review is to clarify the use of angiotensin-converting enzyme inhibitors (ACEIs) and angiotensin II receptor blockers (ARBs) in elderly patients with COVID-19. The high prevalence of heart failure in elderly patients and the coexistence of cytokine storms in patients with COVID-19 may be the opportunity to switch therapy with ACEIs or ARBs to sacubitril/valsartan to exploit the anti-inflammatory potential of neprilysin inhibition and RAAS modulation.

A comprehensive literature search was performed through MEDLINE, MEDLINE In-Process and Other Non-Indexed Citations. EMBASE, PubMed, and the Cochrane Central Register of Controlled Trials were searched through the Ovid interface to identify Englishlanguage articles published from 1 December 2019 to 29 May 2020. In all electronic databases, the following search strategy was implemented and the following keywords (in the title/abstract) were used: 'COVID-19', 'SARSCoV-2', 'coronavirus', 'angiotensin-converting enzyme 2' OR 'ACE2', 'renin-angiotensin-aldosterone system' OR 'RAAS', 'angiotensin-converting enzyme inhibitors' OR 'ACEi', 'angiotensin-receptor blockers' OR 'ARBs', 'Elderly' OR 'Older Adults', 'Hypertension', 'Cytokines' OR 'Cytokine storm', 'Sacubitril/Valsartan' and 'Neprilysin' OR 'NEP'.

Regular alerts were also established. The electronic search strategy was complemented by a direct, manual review of the references.

Search results were combined and duplicates removed. Studies were first screened on the basis of title and abstract, and the full text was then reviewed. Two reviewers (DA and GC) independently performed the revision, while discrepancies were solved by consensus, involving an additional author (RAI). The methodological quality of the included studies was assessed by the authors.

No statistical analysis was conducted due to the heterogeneity of the selected papers. Some data were obtained from both human and animal studies, and this invalidates the direct transfer of conclusions from animals to humans.

\section{Potential Confounding by Age and Hypertension in Coronavirus Disease 2019 (COVID-19) Patients}

\subsection{COVID-19 and Older Adults with Comorbidities}

Older people, often frail and with several comorbidities, are at highest risk for severe and fatal forms of COVID-19 [2-4]. Experience from Italy shows a median age at death of 79 years for men and 82 years for women [5]. On 11 March 2020, the World Health Organization (WHO) declared the COVID-19 outbreak a 'pandemic', and on 2 April 2020, the death rate was double that of severe acute respiratory syndrome (SARS) in 2002-2003 and Middle-East respiratory syndrome (MERS) in 2013 combined. This pandemic seemed to be expanding at an exponential rate, doubling the number of positive cases every $43 \mathrm{~h}$.

New COVID-19 populations are generally liable, but elderly people with underlying diseases are more susceptible. Diabetes, hypertension, obesity, cardiovascular disease, and cerebrovascular disease are the most important comorbidities involved in the degeneration of clinical conditions of patients with COVID-19 [3, 4, 6, 7]. The elderly are more prone to SARS-CoV-2, are more frequently admitted to intensive care units (ICUs), and have higher mortality rates $[8,9]$. Yang et al. [10] found that 52\% of their COVID-19 population was older than 60 years of age and were more likely to have chronic medical illnesses. Similar results were also published by Yang et al. [11].

\subsection{COVID-19 and Hypertension}

Hypertension has been detected as a common comorbidity in viral pneumonia and is already one of the most relevant features associated with mortality, before the COVID-19 pandemic [12]. These data have also been confirmed in COVID-19 pneumonia [13, 14]. Nevertheless, a lack of sound evidence that hypertension per se is an independent risk factor for COVID-19 has recently been demonstrated [15]. Potential confounding by age when hypertension was evaluated as a risk factor for the severity of COVID-19 infection has been underscored [16].

SARS-CoV2 uses the angiotensin-converting enzyme 2 (ACE2) receptor to infect host cells [17]. ACE2 is a key enzyme in the renin-angiotensin system $[18,19]$ that regulates blood pressure, fluid and electrolyte balance, and systemic vascular resistance [20]. The strong inhibition of ACE2 by SARS-CoV2 may increase the levels of angiotensin II (Ang II) in the alveolar tissue of the lung, leading to increased vascular permeability and pulmonary edema [21, 22].

In experimental models of hypertension and diabetes, ACE2 enzyme expression was shown to be downregulated. As a consequence, tissue Ang II levels were significantly increased, contributing to hormone-mediated tissue injury and supporting the fact that ACE (enzymatic core of RAAS, which converts Ang I hormone into the active vasoconstrictor Ang II) and ACE2 have counter-regulatory functions [23, 24]. ACE2 messenger RNA (mRNA) is mainly detected in the small intestine, colon, duodenum, kidney, testis, and gallbladder. The overall expression of ACE2 in the lungs is low but it may be upregulated under certain conditions, such as asthma and idiopathic pulmonary fibrosis $[25,26]$. Tissue hypoxia associated with myocardial infarction and cirrhosis may also increase ACE2 expression in both humans and rats [27, 28]. Animal 
studies have shown that medications commonly used for hypertension and heart disease to regulate the RAAS, such as ACEIs and ARBs, may increase the expression of ACE2 proteins [29, 30]. It has also been suggested that a population with higher ACE2 expression might be more susceptible to SARS-CoV2 [31]. Furthermore, ACE2 polymorphism could increase the risk of COVID-19 in patients treated with ACEIs or ARBs [32]. Moreover, a very high affinity binding of SARS-CoV2 for ACE2 could explain the low viral burden required to infect a host cell [33]. Nevertheless, ACE2 knockout mice displayed more severe symptoms of ARDS, while overexpression of ACE2 had some protective effects [34]. Based on the assumption that compensation of ACE2 and balancing of the ACE/ ACE2 function may be a way to alleviate virus-induced severe lung injury, Wu suggested testing ACEIs and ARBs to reduce SARS-CoV2 respiratory symptoms [35]. Furthermore, inhibition of the Ang I/Ang II/angiotensin type 1 receptor (AT1R) pathway alleviated inflammatory lung disease [36], and losartan (an ARB drug) administration improved pulmonary vascular remodeling, inhibited smoke-induced right ventricular systolic pressure and Ang II elevations, and partially reversed ACE2 decrease in rat lungs [37]. Moving from theory to practice, ACEIs and ARBs have recently been reported as independent predictors of lower plasma ACE2 concentrations [38]. On the other hand, a first retrospective study did not show any significant differences in fatal outcomes of a limited number of hospitalized COVID-19 patients regardless of whether or not they were receiving ACEI/ARB treatments [39]. Since then, several observational studies have confirmed that ACEI/ARB use does not make COVID19 patients more vulnerable to the virus [40-45]. Nevertheless, when an effect of the ACEI/ARB therapy was detected in COVID-19 patients in these and other studies, it was shown to be more protective than harmful [46-48].

\section{Cross-Talk between Renin-Angiotensin System (RAS) Dysregulation and Cytokine Storm in COVID-19}

SARS-CoV-2 infection is triggered by binding to the ACE2, which is highly expressed in the nasopharynx and lungs, as well as in the cardiovascular system and the gastrointestinal and genitourinary tracts [49]. Although respiratory symptoms usually dominate the clinical presentation of COVID19, SARS-CoV-2 infection could also be responsible for a variety of potentially serious multiorgan manifestations. ACE2 represents a key enzyme for regulating the RAS that degrades Ang II to Ang-(1-7), mitigating its effects on vasoconstriction, sodium retention, and fibrosis [49]. After the initial involvement of ACE2 by the spike-protein SARS$\mathrm{CoV}-2$, there is a subsequent downregulation of ACE2, leading to a reduction in Ang-(1-7) [49], which causes an acute lung injury. Importantly, this lesion can be mitigated in animal models by blocking the renin-angiotensin pathway with ACEIs or ARBs [50].

Serious clinical presentations of SARS-CoV-2 infections are generally associated with rapid viral replication, infiltration of inflammatory cells, and exaggerated release of cytokines (cytokine release syndrome), resulting in multiorgan damage, including ARDS [51, 52]. Patients admitted to ICUs have higher serum levels of monocyte chemoattractant protein-1, granulocyte colony-stimulating factor, granulocyte-macrophage colony-stimulating factor, macrophage inflammatory protein-1 A, interferoninducible protein-10, and tumor necrosis factor (TNF)- $\alpha$ [53], suggesting that the 'intensity' of the 'cytokine storm' modulates the severity of the disease. Beyond the cytokine storm, the lymphocyte count has also been associated with increased disease severity [54].

The SARS-CoV-2-induced imbalance of ACE2/ACE results in AT1R-mediated inflammatory response with activation of the complement system, mitogen-activated protein kinases (MAPK) and nuclear factor kappa B (NF-kB). The decrease in Ang-(1-7) following SARS-CoV-2-mediated ACE2 downregulation seems to play a pivotal pathogenetic role. Thus, Ang-(1-7) should be considered an antiinflammatory molecule modulating the NF- $\mathrm{KB}, \mathrm{MAPK}$, and ERK1/2 pathways. This confirms the view that drugs able to increase Ang-(1-7) could benefit SARS-CoV2 patients.

\section{Age as a Potential Driver of Interventions Targeting the Renin-Angiotensin- Aldosterone System (RAAS)}

Age likely plays a key role as a modulator of the interaction among factors potentially affecting the course of COVID-19. Indeed, 'inflammaging', a type of dysregulated immune response with an exacerbated inflammatory and depressed immunologic component, is a typical feature of aging and may make the elderly more vulnerable to COVID-19, mainly by promoting the cytokine storm [55]. Interestingly, the resistance of bats to the toxic effect of COVID-19 is explained by a well-balanced immune 


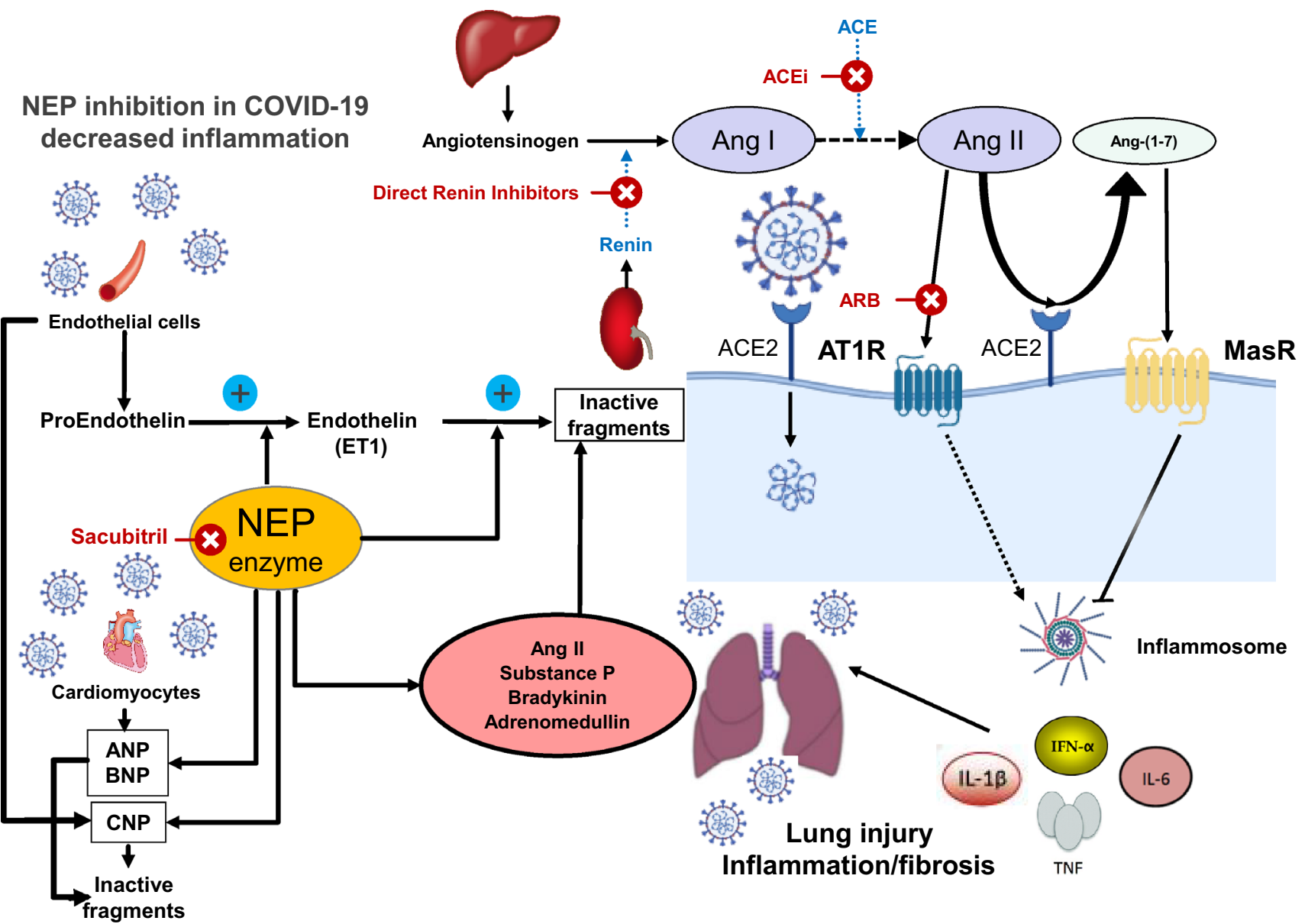

Fig. 1 Double interaction between sacubitril and a neprilysin inhibitor, and between an $\mathrm{ARB}, \mathrm{AT}_{1}$ receptor and Mas receptor, and their impact on the development of inflammatory response due to COVID19 infection. Neprilysin is a neutral endopeptidase and is also known as EC 3.4.24.11 and enkephalinase. It is a plasma membrane-bound zinc metalloprotease initially isolated from renal epithelial brush border cells and cleaves peptide substrates at the amino side of hydrophobic amino acids. It catalyzes the degradation of a number of endogenous vasodilator peptides, including ANPs, BNP, CNP, substance $\mathrm{P}$, bradykinin and adrenomedullin, as well as vasoconstrictor peptides, including ET-1 and Ang II. In addition to degrading vasoactive peptides to inactive breakdown products, neprilysin can also convert big ET-1 to the active peptide ET-1. Therefore, the physiologi-

response with a mild inflammatory component [56]. Furthermore, ACE2 expression in the lungs has been reported to increase with age [57], and, finally, the proportion of fat mass also increases with age [58]. Thus, geriatric patients might also be at greater risk of a cytokine storm if their body mass index does not fall within the obesity range. Indeed, adipose tissue has a proinflammatory effect and Ang II partly mediates it [59]. cal actions of neprilysin in vivo will be to balance its effects on the breakdown of vasodilators and vasoconstrictors, and on the synthesis of ET-1 from big ET-1. Reducing the production of Ang II with ACEIs, or blocking Ang II-AT1R actions with an ARB, enhances the generation of Ang-(1-7) by ACE2 and activation of the MasR, which attenuates inflammation and fibrosis and consequently attenuates lung injury. $A R B$ angiotensin receptor blocker, $A N P s$ atrial natriuretic peptides, $B N P$ B-type natriuretic peptide, $C N P$ C-type natriuretic peptide, ET-1 endothelin-1, Ang angiotensin, ACEIs angiotensin-converting enzyme inhibitors, $A T I R$ angiotensin type 1 receptor, $A C E 2$ angiotensin-converting enzyme 2, MasR Mas receptor, NEP neprilysin, $I L$ interleukin, $I F N$ interferon, $T N F$ tumor necrosis factor

\section{Conclusions}

We have recently hypothesized that early administration of sacubitril/valsartan may have a favorable effect on COVID-19 patients [60] by inhibiting neprilysin and RAAS.

Valsartan will continue to block excessive angiotensinmediated AT1R activation due to the viral infection, and, 
in parallel, will upregulate ACE2, thus increasing Ang(1-7) production.

Sacubitril/valsartan reduced the concentration of proinflammatory cytokines and neutrophil count, while increasing lymphocyte count more than valsartan alone or placebo [61].

In ill patients, such as patients with acute heart failure, sacubitril/valsartan was able to mitigate the inflammatory response and increase the relative lymphocyte count [62].

Steady progress is being made in the treatment of patients hospitalized for COVID-19. The advances come together with the understanding that the disease is far more complex than a simple pneumonia. In the early stages of the disease, modulation of the inflammatory response through the inhibition of neprilysin and modulation of the RAAS could modify the course and outcome of the SARSCoV-2 infection (Fig. 1). This theoretical assumption seems worthy of testing not only in heart failure patients with a recognized indication to sacubitril/valsartan, but also in broader populations, for instance in hypertensive patients affected by COVID-19. However, due to the dysregulated immune response, geriatric patients qualify as the optimal target of interventions with the aim of mitigating the inflammatory response. This would verify whether, at least in selected populations, sacubitril/valsartan may qualify as a further aid against COVID-19.

\section{Declarations}

Funding No external funding was used in the preparation of this manuscript.

Conflicts of Interest/Competing Interests Gerardo Casucci, Domenico Acanfora, and Raffaele Antonelli Incalzi declare they have no potential conflicts of interest that might be relevant to the contents of this manuscript.

Ethics approval Not applicable.

Consent to Participate Not applicable.

Consent for Publication Not applicable.

Availability of Data and Material Not applicable.

Code Availability Not applicable.

Author Contributions Conception and design: Gerardo Casucci, Domenico Acanfora and Raffaele Antonelli Incalzi. Literature search, draft and/or critical revision of the work and approval of the final manuscript: All authors.

\section{References}

1. Coronavirus Map: tracking the global outbreak. The New York Times. Updated 15 May 2020.
2. Zhou F, Yu T, Du R, et al. Clinical course and risk factors for mortality of adult inpatients with COVID-19 in Wuhan, China: a retrospective cohort study. Lancet. 2020;395(10229):1054-62. https://doi.org/10.1016/S0140-6736(20)30566-3.

3. Du RH, Liang LR, Yang CQ, et al. Predictors of mortality for patients with COVID-19 pneumonia caused by SARS-CoV-2: a prospective cohort study. Eur Respir J. 2020;55(5):2000524. https ://doi.org/10.1183/13993003.00524-2020.

4. Liang WH, Guan WJ, Li CC, et al. Clinical characteristics and outcomes of hospitalised patients with COVID-19 treated in Hubei (epicenter) and outside Hubei (non-epicenter): a nationwide analysis of China. Eur Respir J. 2020;55(6):2000562. https://doi. org/10.1183/13993003.00562-2020.

5. Istituto Superiore di Sanità Caratteristiche dei pazienti deceduti positivi a COVID-19 in Italia. 2019. www.epicentro.iss.it/coron avirus/bollettino/Report-COVID-2019_2_aprile_eng.pdf.

6. Sanchis-Gomar F, Lavie CJ, Perez-Quilis C, Henry BM, Lippi G. Angiotensin-converting enzyme 2 and antihypertensives (angiotensin receptor blockers and angiotensin-converting enzyme inhibitors) in coronavirus disease 2019. Mayo Clin Proc. 2020;95(6):1222-300. https://doi.org/10.1016/j.mayoc p.2020.03.026.

7. Sharma A, Garg A, Rout A, Lavie CJ. Association of Obesity With More Critical Illness in COVID-19. Mayo Clin Proc. 2020;95(9):2040-2. https://doi.org/10.1016/j.mayoc p.2020.06.046.

8. Li JY, You Z, Wang Q, et al. The epidemic of 2019-novelcoronavirus (2019-nCoV) pneumonia and insights for emerging infectious diseases in the future. Microbes Infect. 2020;22:80-5. https://doi.org/10.1016/j.micinf.2020.02.002(Epub 2020 Feb 20).

9. Guan WJ, Ni ZY, Hu Y, et al. Clinical characteristics of 2019 novel coronavirus infection in China. N Engl J Med. 2020;382:1708-20. https://doi.org/10.1056/NEJMoa2002032.

10. Yang X, Yu Y, Xu J, et al. Clinical course and outcomes of critically ill patients with SARS-CoV-2 pneumonia in Wuhan, China: a single-centered, retrospective, observational study. Lancet Respir Med. 2020;8:475-81.

11. Yang J, Zheng Y, Gou X, et al. Prevalence of comorbidities in the novel Wuhan coronavirus (Covid-19) infection: a systematic review and meta-analysis. Int J Infect Dis. 2020;9712(20):3013643. https://doi.org/10.1016/j.ijid.2020.03.017.

12. Guo L, Wei D, Zhang X, Wu Y, Li Q, Zhou M, Qu J. Clinical features predicting mortality risk in patients with viral pneumonia: the MuLBSTA score. Front Microbiol. 2019;10:1-10.

13. Zhou F, Yu T, Du R, et al. Clinical course and risk factors for mortality of adult inpatients with COVID-19 in Wuhan, China: a retrospective cohort study. The Lancet. 2020;395:1054-62.

14. Wu C, Chen X, Cai Y, Xia J, et al. Risk factors associated with acute respiratory distress syndrome and death in patients with coronavirus disease 2019 pneumonia in Wuhan, China. JAMA Intern Med. 2020;180(7):1-11. https://doi.org/10.1001/jamai nternmed.2020.0994.

15. Kreutz R, Abd-El-Hady AE, Azizi M, et al. Hypertension, the renin-angiotensin system, and the risk of lower respiratory tract infections and lung injury: implications for COVID-19. Cardiov Res. 2020. https://doi.org/10.1093/cvr/cvaa097.

16. Matsushita K, Ding N, Kou M, et al. The relationship of COVID-19 severity with cardiovascular disease and its traditional risk factors: A systematic review and meta-analysis. medRxiv. 2020. https://doi.org/10.1101/2020.04.05.20054155.

17. Wu F, Zhao S, Yu B, Chen Y-M, et al. A new coronavirus associated with human respiratory disease in China. Nature. 2020;579(7798):265-9. https://doi.org/10.1038/s4158 6-020-2008-3. 
18. Donoghue M, Hsieh F, Baronas E, et al. A novel angiotensinconverting enzyme-related carboxypeptidase (ACE2) converts angiotensin i to angiotensin 1-9. Circ Res. 2000;87:e1-e9.

19. Tipnis SR, Hooper NM, Hyde R, et al. A human homolog of angiotensin-converting enzyme cloning and functional expression as a captopril-insensitive carboxypeptidase. J Biol Chem. 2000;275:33238-43.

20. Yagil Y, Yagil C. Hypothesis ACE2 modulates blood pressure in the mammalian organism. Hypertension. 2003;41:871-3.

21. Marshall RP. The pulmonary renin-angiotensin system. Curr Pharm Des. 2003;9:715-22.

22. Kuba K, Imai Y, Penninger JM. Angiotensin-converting enzyme 2 in lung diseases. Curr Opin Pharmacol. 2006;6:271-6.

23. Crackower M, Sarao R, Oudit G, et al. Angiotensin-converting enzyme 2 is an essential regulator of heart function. Nature. 2002;417:822-8.

24. Tikellis C, Johnston CI, Forbes JM, et al. Characterization of renal angiotensin-converting enzyme 2 in diabetic nephropathy. Hypertension. 2003;41:392-7.

25. Vieira Braga FA, Kar G, Berg M, et al. A cellular census of human lungs identifies novel cell states in health and in asthma. Nat Med. 2019;25:1153-63.

26. Xu Y, Mizuno T, Sridharan A, et al. Single-cell RNA sequencing identifies diverse roles of epithelial cells in idiopathic pulmonary fibrosis. JCI Insight. 2016;1(20):e90558.

27. Burrell LM, Risvanis J, Kubota E, et al. Myocardial infarction increases ACE2 expression in rat and humans. Eur Heart J. 2005;26:369-75.

28. Paizis G, Tikellis C, Cooper ME, et al. Chronic liver injury in rats and humans upregulates the novel enzyme angiotensin converting enzyme 2 . Gut. 2005;54:1790-6.

29. Mou H, Raj VS, van Kuppeveld FJM, et al. The receptor binding domain of the new MERS coronavirus maps to a 231-residue region in the spike protein that efficiently elicits neutralizing antibodies. J Virol. 2013;13:1277-313.

30. Li XC, Zhang J, Zhuo JL. The vasoprotective axes of the reninangiotensin system: physiological relevance and therapeutic implications in cardiovascular, hypertensive and kidney diseases. Pharmacol Res. 2017;125:21-38.

31. Zhao Y, Zhao Z, Wang Y, et al. Single-cell RNA expression profiling of ACE2, the putative receptor of Wuhan 2019-nCov. BioRxiv. 2020. https://doi.org/10.1101/2020.01.26.919985.

32. Fang L, Karakiulakis G, Roth M. Are patients with hypertension and diabetes mellitus at increased risk for COVID-19 infection? Lancet Respir Med. 2020;8(4):e21. https://doi.org/10.1016/PII.

33. Chen Y, Guo Y, Pan Y, et al. Structure analysis of the receptor binding of 2019-nCoV. Biochem Biophys Res Commun. 2020;525:135-40.

34. Imai Y, Kuba K, Rao S, et al. Angiotensin-converting enzyme 2 protects from severe acute lung failure. Nature. 2005;436:112-6.

35. Wu Y. Compensation of ACE2 function for possible clinical management of 2019-nCoV-induced acute lung injury. Virol Sin. 2020;35:256-8. https://doi.org/10.1007/s12250-020-00205-6.

36. Kuba K, Imai Y, Rao S, et al. A crucial role of angiotensin converting enzyme 2 (ACE2) in SARS coronavirus-induced lung injury. Nat Med. 2005;11:875-9.

37. Han SX, He GM, Wang T, et al. Losartan attenuates chronic cigarette smoke exposure-induced pulmonary arterial hypertension in rats: possible involvement of angiotensin-converting enzyme-2. Toxicol Appl Pharmacol. 2010;245:100-7.

38. Sama IE, Ravera A, Santema BT, et al. Circulating plasma concentrations of angiotensin-converting enzyme 2 in men and women with heart failure and effects of renin-angiotensinaldosterone inhibitors. Eur Heart J. 2020;41:1810-7. https://doi. org/10.1093/eurheartj/ehaa373.
39. Guo T, Fan Y, Chen M, et al. Cardiovascular implications of fatal outcomes of patients with coronavirus disease 2019 (COVID-19). JAMA Cardiol. 2020;5(7):811-8. https://doi.org/10.1001/jamac ardio.2020.1017(Published online March 27, 2020).

40. Mehta N, Kalra A, Nowacki AS, et al. Association of use of angiotensin-converting enzyme inhibitors and angiotensin II receptor with testing positive for coronavirus disease 2019 (COVID-19). JAMA Cardiol. 2020;5(9):1020-6. https://doi.org/10.1001/jamac ardio.2020.1855.

41. Li J, Wang X, Chen J, Zhang H, Deng A. Association of reninangiotensin system inhibitors with severity or risk of death in patients with hypertension hospitalized for coronavirus disease 2019 (COVID-19) infection in Wuhan, China. JAMA Cardiol. 2020;5(7):825-30. https://doi.org/10.1001/jamacardio.2020.1624.

42. Reynolds H, Samrachana A, Pulgarin C, Troxel AB, et al. Reninangiotensin-aldosterone system inhibitors and risk of Covid-19. N Engl J Med. 2020;382(25):2441-8. https://doi.org/10.1056/ NEJMoa2008975.

43. Mancia G, Rea F, Ludergnani M, et al. Renin-angiotensin-aldosterone system blockers and the risk of Covid-19. N Engl J Med. 2020;382(25):2431-40. https://doi.org/10.1056/NEJMoa2006923.

44. Mehra MR, Desai SS, Kuy SR, et al. Cardiovascular disease, drug therapy, and mortality in Covid-19. N Engl J Med. 2020;382(25):e102. https://doi.org/10.1056/NEJMoa2007621.

45. De Abajo F, Rodriguez-Martin S, Lema V, et al. Use of reninangiotensin-aldosterone system inhibitors and risk of Covid-19 requiring admission to hospital: a case-population study. The Lancet. 2020;395(10238):1705-14. https://doi.org/10.1016/S0140 -6736(20)31030-8.

46. Zhang P, Zhu L, Cai J, Lei F, et al. Association of inpatient use of angiotensin-converting enzyme inhibitors and angiotensin II blockers with mortality among patients with hypertension hospitalized with COVID-19. Circ Res. 2020;126(12):1671-81. https ://doi.org/10.1161/CIRCRESAHA.120.317134.

47. Meng J, Xiao G, Zhang J, He X, et al. Renin-angiotensin system inhibitors improve the clinical outcome of COVID-19 patients with hypertension. Emerg Microb Infect. 2020;9(1):757-60. https ://doi.org/10.1080/22221751.2020.1746200.

48. Amat-Santos J, Santos-Martinez S, López-Otero D, NombelaFranco L, et al. Ramipril in high-risk patients with COVID-19. J Am Coll Cardiol. 2020;76(3):268-76.

49. Vaduganathan M, Vardeny O, Michel T, McMurray JJV, Pfeffer MA, Solomon SD. Renin-angiotensin-aldosterone system inhibitors in patients with Covid-19. N Engl J Med. 2020;382:1653-9.

50. Kuba K, Imai Y, Rao S, et al. A crucial role of angiotensin converting enzyme 2 (ACE2) in SARS coronavirus-induced lung injury. Nat Med. 2005;11:875-9.

51. Pedersen SF, Ho YC. SARS-CoV-2: a storm is raging. J Clin Invest. 2020;130(5):2202-5. https://doi.org/10.1172/JCI137647.

52. Mehta P, McAuley DF, Brown M, Sanchez E, Tattersall RS, Manson JJ. COVID-19: consider cytokine storm syndromes and immunosuppression. Lancet. 2020;395:1033-4.

53. Huang C, Wang Y, Li X. Clinical features of patients infected with 2019 novel coronavirus in Wuhan, China. Lancet. 2020;395:497-506.

54. Yang X, Yu Y, Xu J, Shu H, et al. Clinical course and outcomes of critically ill patients with SARS-CoV-2 pneumonia in Wuhan, China: a single-centered, retrospective, observational study. Lancet Respir Med. 2020;8(5):475-81. https://doi.org/10.1016/S2213 $-2600(20) 30079-5$.

55. Franceschi C, Garagnani P, Parini P, Giuliani C, Santoro A, Franceschi $\mathrm{C}$, et al. Inflammaging: a new immune-metabolic viewpoint for age-related diseases. Nat Rev Endocrinol. 2018;14(10):576-90. 
56. Brook CE, Boots M, Chandran K, et al. Accelerated viral dynamics in bat cell lines, with implications for zoonotic emergence. Elife. 2020;9:e48401. https://doi.org/10.7554/eLife .48401 .

57. Chen Y, Li L. SARS-CoV-2: virus dynamics and host response. Lancet Infect Dis. 2020;20(5):515-6. https://doi.org/10.1016/ S1473-3099(20)30235-8.

58. He X, Li Z, Tang X, Zhang L, et al. Age- and sex-related differences in body composition in healthy subjects aged 18 to 82 years. Med (Baltim). 2018;97(25):e11152. https://doi.org/10.1097/ MD.0000000000011152.

59. Bourgonje AR, Abdulle AE, Timens W, et al. Angiotensinconverting enzyme 2 (ACE2), SARS-CoV-2 and the pathophysiology of coronavirus disease 2019 (COVID-19). J Pathol. 2020;251(3):228-48. https://doi.org/10.1002/path.5471.
60. Acanfora D, Ciccone MM, Scicchitano P, Acanfora C, Casucci G. Neprilysin inhibitor-angiotensin II receptor blocker combination (sacubitril/valsartan): rationale for adoption in SARS-CoV-2 patients. Eur Heart J Cardiovasc Pharmacother. 2020;6:135-6. https://doi.org/10.1093/ehjcvp/pvaa028.

61. Zhang H, Liu G, Zhou W, Zhang W, Wang K, Zhang J. Neprilysin inhibitor-angiotensin II receptor blocker combination therapy (sacubitril/valsartan) suppresses atherosclerotic plaque formation and inhibits inflammation in apolipoprotein E-deficient Mice. Sci Rep. 2019;9:6509.

62. Acanfora D, Scicchitano P, Acanfora C, Maestri R, Goglia F, Incalzi RA, et al. Early initiation of sacubitril/valsartan in patients with chronic heart failure after acute decompensation: a case series analysis. Clin Drug Investig. 2020;40(5):493-501. https:// doi.org/10.1007/s40261-020-00908-4. 